\title{
Formation of Cerium-Filled Skutterudite Thermoelectric Materials Sintered from Gas-Atomized Powder*1
}

\author{
Hiroyuki Tanahashi ${ }^{1, * 2}$, Yoriko Ohta ${ }^{1}$, Hiroshi Uchida ${ }^{1, * 3}$, Yoshio Itsumi ${ }^{2}, * 4$, \\ Akio Kasama ${ }^{1}$ and Kakuei Matsubara ${ }^{3}$ \\ ${ }^{1}$ Japan Ultra-high Temperature Materials Research Institute, Ube 755-0001, Japan \\ ${ }^{2}$ Materials Research Laboratory, Kobe Steel, LTD., Kobe 651-2271, Japan \\ ${ }^{3}$ Department of Electronics and Computer Science, Science University of Tokyo in Yamaguchi, Onoda 756-0884, Japan
}

A process for forming the Ce-filled skutterudite thermoelectric materials sintered from gas-atomized powder has been investigated. The rapidly cooled particles obtained by the Ar gas-atomizing method consist of the phases of $\mathrm{CeFe}_{3} \mathrm{CoSb}_{12}$ ( $\mathrm{skutterudite}$ ), $\mathrm{FeSb}_{2}, \mathrm{FeSb}$ and $\mathrm{Sb}$. The differential scanning calorimetry curve indicates that sintering proceeded through the two exothermic reactions: one due to the oxidation of $\mathrm{Sb}$ at low temperatures and the other due to the skutterudite phase formation from three phases of $\mathrm{FeSb}_{2}, \mathrm{FeSb}$ and $\mathrm{Sb}$ at high temperatures. On the basis of these results, sintering conditions were best tuned to reduce the oxidation of Sb while ensuring the skutterudite phase formation. Consequently, it becomes possible to increase the Seebeck coefficient, and to decrease the thermal conductivity in the temperature range of $300-850 \mathrm{~K}$. We consider the achievement of favorable results to be mainly attributed to a decrease in the Sb phase remaining in sintered materials.

(Received November 29, 2001; Accepted March 20, 2002)

Keywords: cobalt-antimonide, cerium-filling, skutterudite, thermoelectric material, gas-atomizing, differential scanning calorimeter, sintering, formation process

\section{Introduction}

$\mathrm{CoSb}_{3}$-based skutterudite compounds are known as excellent thermoelectric materials. ${ }^{1)} \mathrm{CeFe}_{3} \mathrm{CoSb}_{12}$, one of "filledskutterudite", which is derived from $\mathrm{CoSb}_{3}$ by partially replacing the Co atoms with $\mathrm{Fe}$ atoms and filling cavities in the crystal lattice of $\mathrm{CoSb}_{3}$ with Ce atoms, has received particular attention because of its high thermoelectric efficiency, especially at high temperatures. $^{2 \text { ) }}$

These materials have been conventionally prepared by the powder metallurgy technique, and the powder as a starting material is generally obtained by the method of both melting and grinding and/or mechanical milling of the raw materials. ${ }^{3,4)}$ However, these methods seem to be suitable only on a laboratory-scale but not on a commercial-scale. Several attempts have been proposed such as the application of a gas-atomizing method to powder production. The thermoelectric properties of the materials sintered from the powder have been reported. ${ }^{5)}$ In our previous investigation, ${ }^{5)}$ it was pointed out that a combined process of gas-atomizing and sintering is a promising on a production scale. However the sintering condition was not optimized at that time, and the characterization of the atomized powder particles and clarification of the formation process of these materials are required to establish the optimum sintering condition.

In order to appraise the newly adjusted sintering conditions,

${ }^{* 1}$ Part of this Paper was Presented at the Spring Meeting of the Japan Institute of Metals, held in Narashino on March 29, 2001. This Paper was Originally published in Japanese in J. Japan Inst. Metals, 65 (2001) 955-960.

${ }^{* 2}$ Present address: Steel Research Laboratory, Nippon Steel Corporation, Futtsu 293-8511, Japan.

${ }^{* 3}$ Present address: Polymer Laboratory, Ube Industries, LTD., Ichihara 290-0045, Japan.

${ }^{* 4}$ Present address: Technical Development Group, Kobe Steel, LTD., Tokyo 141-8688, Japan. the characterization of gas-atomized powder, the process of forming the skutterudite phase of $\mathrm{CeFe}_{3} \mathrm{CoSb}_{12}$, and the thermoelectric properties of the materials sintered under varying conditions have been investigated in the present study. The difference between the properties of laboratory-scale materials and atomizing-featured ones is also discussed.

\section{Experimental Procedure}

Two kinds of powders were produced by gas-atomization. Chemical compositions of those materials in weighing are listed in Table 1. $\mathrm{CoSb}_{3}$ was atomized for comparison. In this table, the value of $\mathrm{Sb}$ is normalized to 3 in the case of $\mathrm{CoSb}_{3}$, and the total amount of $\mathrm{Fe}, \mathrm{Co}$ and $\mathrm{Sb}$ is also normalized to 16 for $\mathrm{CeFe}_{3} \mathrm{CoSb}_{12}$.

Authors pointed that controlling the chemical compositions of atomized powder close to stoichiometry might not be the best way to achieve better thermoelectric properties only in the combination process of gas-atomizing and sintering. ${ }^{6)} \mathrm{A}$ slight amount of excess Sb over stoichiometry is rather effective for reducing the forming of Ce-rich portions on grain boundaries of compounds. ${ }^{6)}$ In present study, therefore $\mathrm{Sb}$ was weighted with a slightly rich composition than that in stoichiometry for the reason described above and in order to compensate for the vaporizing loss during melting.

Table 1 Chemical compositions of specimens.

\begin{tabular}{llllll}
\hline Specimen & & $\mathrm{Ce}$ & $\mathrm{Fe}$ & $\mathrm{Co}$ & $\mathrm{Sb}$ \\
\hline \multirow{2}{*}{$\mathrm{CoSb}_{3}$} & Weighed & - & - & 0.94 & 3 \\
& Analyzed & - & - & 0.81 & 3 \\
\hline \multirow{2}{*}{$\mathrm{CeFe}_{3} \mathrm{CoSb}_{12}$} & Weighed & 0.90 & 2.74 & 0.92 & 12.34 \\
& Analyzed & 0.94 & 2.74 & 0.92 & 12.34 \\
\hline
\end{tabular}


Gas-atomization was carried out in the following manner. Ce ingots with a purity of $99.95 \%, \mathrm{Fe}$ ingots with a purity of $99.99 \%$, Co flakes with a purity of $99.9 \%$ and $\mathrm{Sb}$ ingots with purity of over $99.999 \%$ were used as raw materials. The weighed metals were melted in a graphite crucible with a high-frequency induction furnace. Melting took place in vacuum below $473 \mathrm{~K}$, and in a pure $\operatorname{Ar}(99.999 \%)$ atmosphere above $473 \mathrm{~K}$. In this experiment, $\mathrm{Fe}$, Co and $\mathrm{Sb}$ were melted initially, and then $\mathrm{Ce}$ was added to the liquid metal mixture of $\mathrm{Fe}-\mathrm{Co}-\mathrm{Sb}$ at $1473 \mathrm{~K}$ to avoid the formation of $\mathrm{CeSb}$ with a high melting point. The liquid materials were injected through a nozzle capillary by a surge pressure of $0.18 \mathrm{MPa}$, and then a fast Ar gas jet with a pressure of 4.9 MPa blew the liquid stream off. In this manner, rapidly cooled and spherical particles were obtained. Fine particles of less than $100 \mu \mathrm{m}$ in diameter were selected in an Ar atmosphere for sintering and analyses.

Chemical compositions were analyzed by using inductively coupled plasma spectrometry (ICP). Optical microscopy (OM), an electron probe microanalyzer (EPMA) and X-ray diffraction (XRD) were used to identify the phases of the atomized powder. Differential scanning calorimetry (DSC) was performed from $300 \mathrm{~K}$ to a maximum temperature of $973 \mathrm{~K}$ to detect a phase transformation during sintering. Measurements of DSC were done at a heating rate of $0.67 \mathrm{~K} / \mathrm{s}$ using alumina pans. X-ray line profiles of the atomized powder were also examined in the same temperature range.

Two kinds of powder were sintered by the spark plasma sintering method. Cylindrical specimens of $20 \mathrm{~mm}$ in diameter and $10 \mathrm{~mm}$ in height were formed in a graphite mold. Sintering was conducted at $873 \mathrm{~K}$ or $923 \mathrm{~K}$ for $1.8 \mathrm{ks}$ under the pressure of $30 \mathrm{MPa}$ in $\mathrm{Ar}$ or vacuum.

Sintered materials were characterized by using OM, EPMA and XRD. The Seebeck coefficient $(\alpha)$ and the electrical conductivity $(\sigma)$ were measured as a function of temperature in the range from $300 \mathrm{~K}$ to about $873 \mathrm{~K}$ utilizing a rectangular column specimen of $15 \mathrm{~mm}$ in height and $3 \mathrm{~mm}$ square in cross section. The thermoelectromotive force $(v)$ and the temperature difference $(\delta T)$ between two points of the specimen were measured by using a pair of Chromel wires and thermocouples (type $\mathrm{K}$ ), respectively. $\delta T$ was chosen as 3 to $5 \mathrm{~K}$ under ordinary conditions. $\alpha$ was obtained as the quotient of $v$ over $\delta T$. A standard four-probe method utilizing a DC current was used for measurements of $\sigma$. The thermal diffusion coefficient $(\lambda)$ and the specific heat $(c)$ of the sample of $10 \mathrm{~mm}$ in diameter and $2 \mathrm{~mm}$ in thickness were measured by the laser-flash method at room temperature and in the range from 473 to $873 \mathrm{~K}$ at intervals of $100 \mathrm{~K}$. The thermal conductivity $(\kappa)$ was calculated from the formula $\kappa=\lambda c \rho$, where $\rho$ is density.

\section{Results and Discussion}

\subsection{Characterization of atomized powder and skutteru- dite formation}

The analyzed chemical compositions of gas-atomized powders are shown in Table 1. As explained below, as-atomized powder particles consist of plural phases. These analyzed compositions, therefore, indicate averaged values.

Figure 1(a) represents the DSC curve of $\mathrm{CoSb}_{3}$ from 300

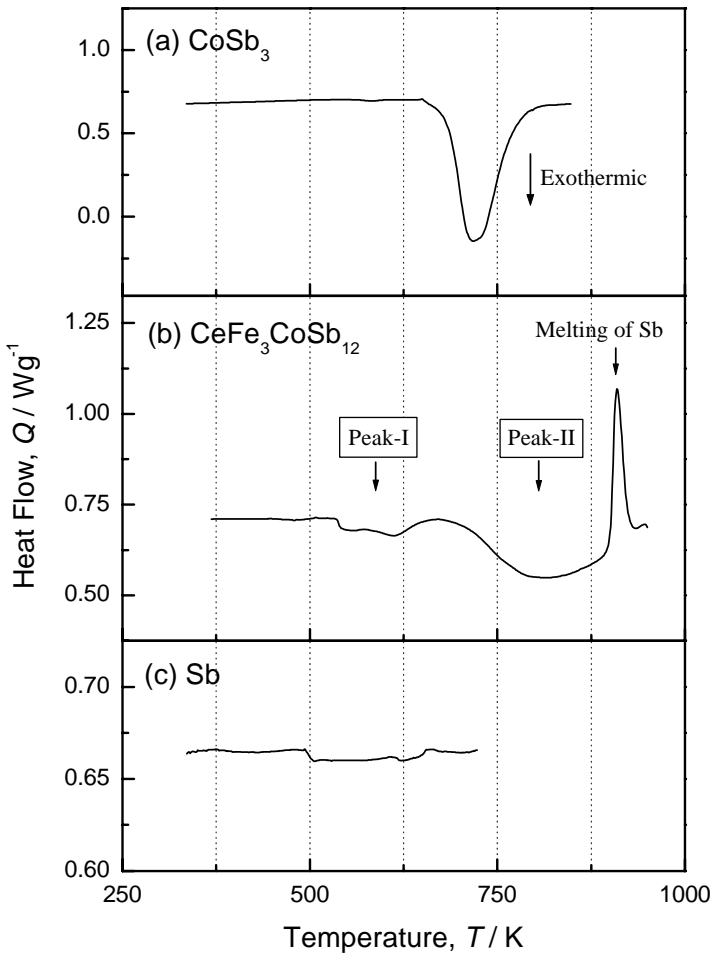

Fig. 1 DSC curves for (a) as-atomized $\mathrm{CoSb}_{3}$, (b) as-atomized $\mathrm{CeFe}_{3} \mathrm{CoSb}_{12}$ and (c) pure-Sb.

to $873 \mathrm{~K}$. An exothermic peak is observed in the temperature range from 650 to $800 \mathrm{~K}$. Uchida et al. ${ }^{5)}$ reported that asatomized $\mathrm{CoSb}_{3}$ powder particles consisted of $\mathrm{CoSb}, \mathrm{CoSb}_{2}$ and $\mathrm{Sb}$. The $\mathrm{CoSb}_{3}$ skutterudite phase formation from these three phases took place through the temperature elevation to $873 \mathrm{~K}$ during sintering. Since the powder particles used in this study involve the same phases as the three phases above, it is considered that the exothermic peak corresponds to the $\mathrm{CoSb}_{3}$ skutterudite formation reaction. In comparison with $\mathrm{CoSb}_{3}$, the DSC curve of $\mathrm{CeFe}_{3} \mathrm{CoSb}_{12}$ is slightly more complex, as shown in Fig. 1(b). There is a small exothermic reaction (peak-I), which seems to be induced by a group of two or more reactions, in the temperature range of 530 to $650 \mathrm{~K}$. After the peak-I, another exothermic reaction (peak-II) occurs from 680 to $950 \mathrm{~K}$. This peak most likely corresponds to the $\mathrm{CeFe}_{3} \mathrm{CoSb}_{12}$ skutterudite formation judging from the case for $\mathrm{CoSb}_{3}$. The reaction however continues over a broader temperature range than that of $\mathrm{CoSb}_{3}$, and furthermore the end of the reaction shifts to a higher temperature than the endothermic peak due to melting of $\mathrm{Sb}$.

In order to identify the phase transformation associated with these exothermic peaks, XRD was measured at the temperatures of $300 \mathrm{~K}, 523 \mathrm{~K}$ (just below the onset of the peak-I), $573 \mathrm{~K}$ (the center of the peak-I), $673 \mathrm{~K}$ (just above the end of the peak-I), $773 \mathrm{~K}$ and $873 \mathrm{~K}$. Line profiles obtained at the respective temperatures are shown in Fig. 2. As is obvious from Fig. 2, some peaks are weakened and disappear during heating, and a single skutterudite phase is eventually formed. Apparently, there are several peaks, relative intensity ratios of which are almost kept constant during heating, such as the peaks indicated by solid circles in Fig. 2.

Judging from these results for the case of $\mathrm{CeFe}_{3} \mathrm{CoSb}_{12}$, we tend to believe that a part of the skutterudite phase al- 


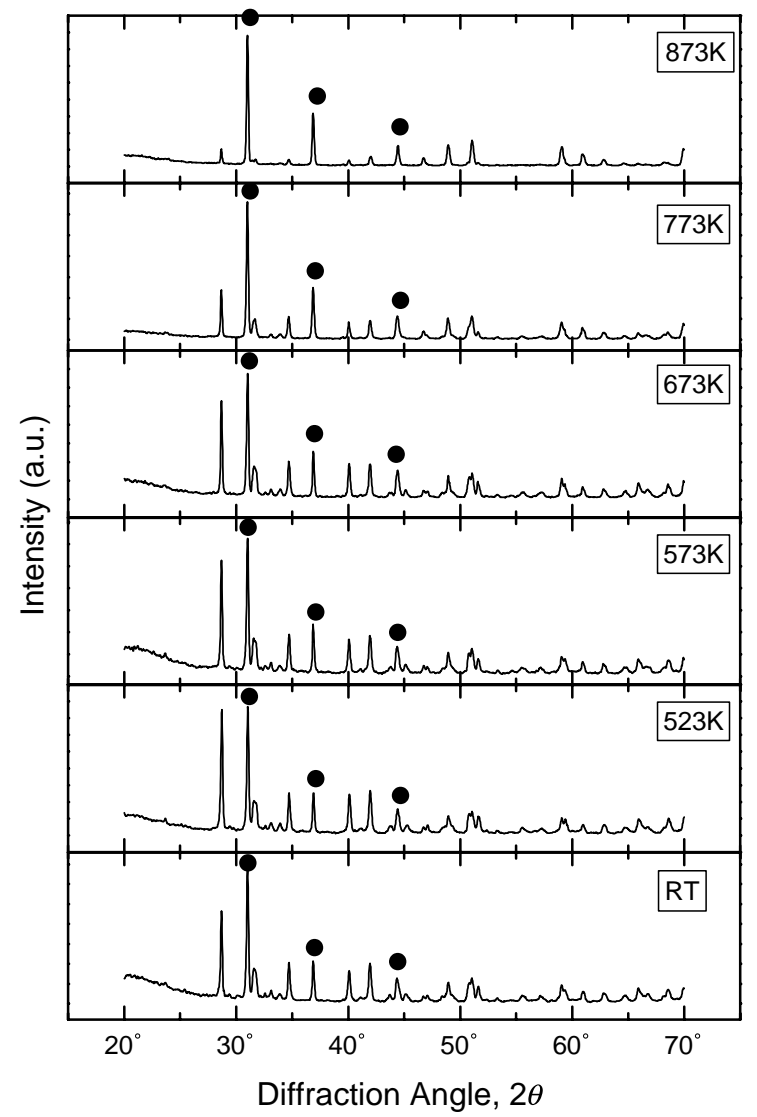

Fig. 2 Change of XRD profiles of the atomized powder from room temperature (RT) to $873 \mathrm{~K}$ during heating. Relative intensity ratios of the peaks indicated by solid circles are kept constant during heating. And these peaks belonged to the diffractions from $\mathrm{CeFe}_{3} \mathrm{CoSb}_{12}$ skutterudite structure.

ready exists in as-atomized particles and its formation from the remaining phases is accelerated during sintering, which is clearly different from the case of $\mathrm{CoSb}_{3}$. Therefore, the peaks of the XRD profile for the as-atomized powder can be consistently identified as consisting of four phases of skutterudite, $\mathrm{FeSb}_{2}, \mathrm{FeSb}$ and $\mathrm{Sb}$, as shown in Fig. 3. Since the lattice parameter of the skutterudite phase is definitely expanded by filling of $\mathrm{Ce},{ }^{7)}$ peaks shift to lower angles than those of $\mathrm{CoSb}_{3}$. FeSb 2 represents in the $\mathrm{FeS}_{2}$ type structure $\left(\mathrm{FeSb}_{2}, \mathrm{CoSb}_{2}\right.$ and $\left.\mathrm{CeSb}_{2}\right)$ and $\mathrm{FeSb}$ represents in the $\mathrm{CoSb}$ type structure ( $\mathrm{FeSb}$ and $\mathrm{CoSb}$ ). Both groups give rise to diffraction patters similar to each other in the group and cannot be distinguished from the measured spectrum.

Figure 4 represents the temperature dependence of intensities of the three specific peaks (marked with open arrows in Fig. 3) normalized with respect to the highest peak of the skutterudite phase (marked with a solid arrow). All intensities exhibit a plateau up to $673 \mathrm{~K}$ with subsequent monotonous decrease with increasing temperature. This result indicates that the peak-I on the DSC curve has nothing to do with the skutterudite formation, while the peak-II should correspond to the skutterudite formation.

The microstructures of heat-treated powders obtained in the several stages during DSC measurement and that of asatomized particles were investigated. Figure 5(a) shows an optical micrograph of as-atomized particles. From the results of EPMA, it is determined that the gray areas represent a mix-

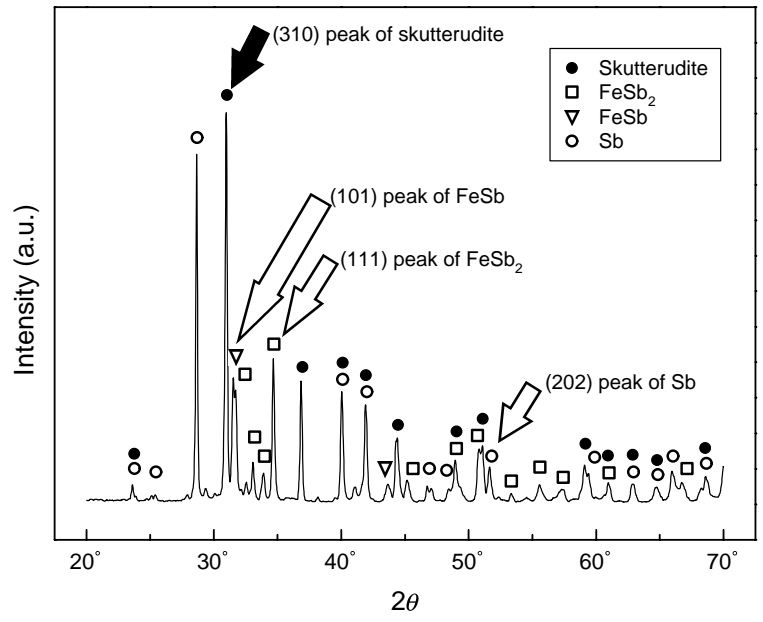

Fig. 3 XRD profile of as-atomized $\mathrm{CeFe}_{3} \mathrm{CoSb}_{12}$ powder.

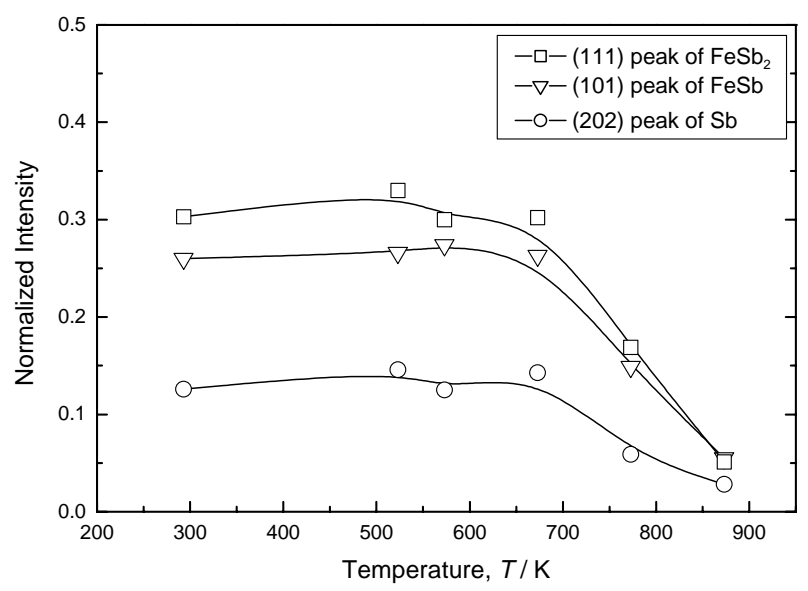

Fig. 4 Temperature dependence of intensities of three specific peaks normalized by the (310) peak of skutterudite from RT to $873 \mathrm{~K}$.

ture of skutterudite, $\mathrm{FeSb}_{2}$ and $\mathrm{FeSb}$, and the white portions correspond to $\mathrm{Sb}$. Black and acicular structures were identified as the Ce-oxide. As compared with the as-atomized powder, the microstructures of the powders heated up to $523 \mathrm{~K}$, $573 \mathrm{~K}$ and $673 \mathrm{~K}$ are similar to that of the as-atomized powder. Although segmentations of Ce oxides are observed in some parts of the powder heated to $773 \mathrm{~K}$, the micro-structural elements are similar to those of the as-atomized powder as shown in Fig. 5(b). No essential change could be detected in the $\mathrm{XRD}$ profiles in the temperature range up to the end of the peak-I. Since the peak-I accompanies any micrographic or structural change, it will be conjectured that the peak-I corresponds to the oxidation of elements involved. We carried out the DSC measurement for Sb fine powder of less than $100 \mu \mathrm{m}$ in diameter under the same condition as that for the atomized powders. An exothermic reaction was observed as shown in Fig. 1(c). From the results of XRD for the powder after DSC measurement, this reaction was judged as the oxidation of $\mathrm{Sb}$. In comparison between this reaction and the peak-I, heat flow of each reaction are approximately similar, whereas the temperature range are slightly different. Therefore, it is highly likely that the peak-I corresponds to the oxidation reaction of pure $\mathrm{Sb}$ remaining in the atomized particles. 


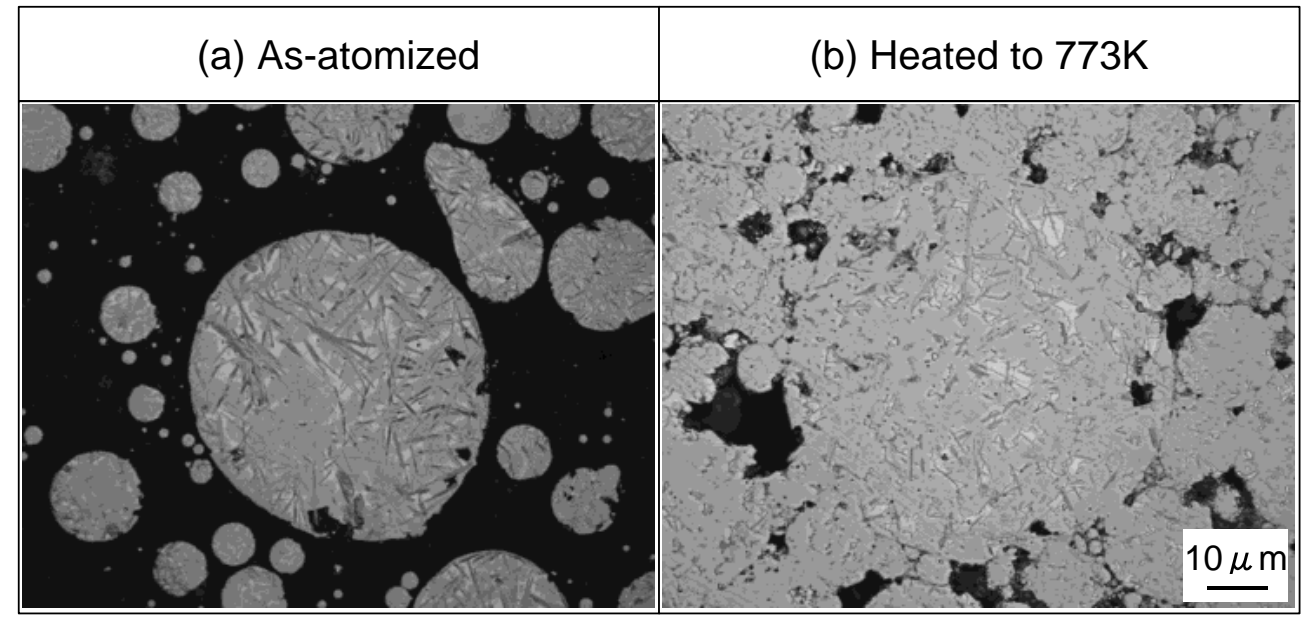

Fig. 5 (a) Microstructure of as-atomized $\mathrm{CeFe}_{3} \mathrm{CoSb}_{12}$ particles. Gray areas represent a mixture of skutterudite, FeSb 2 and FeSb. White portions correspond to $\mathrm{Sb}$. Black and acicular structures are identified as Ce-oxides. (b) Microstructure of the powder heated to $773 \mathrm{~K}$ The micro-structural elements are similar to those of the as-atomized powder. Segmentations of Ce oxides are observed in some parts.

\subsection{Sintering and thermoelectric properties}

As discussed in Section 3.1, the sintering process of gasatomized $\mathrm{CeFe}_{3} \mathrm{CoSb}_{12}$ powder involves the stages of the oxidation of $\mathrm{Sb}$ and the formation of the skutterudite phase. From this point of view, the sintering condition was elucidated in comparison with that of Uchida et al. ${ }^{5)}$ In their work, the experiments had been done in an Ar gas atmosphere at the temperature of $873 \mathrm{~K}$ in order to avoid the vaporization of Sb. In the present study, the sintering was carried out under vacuum to minimize the oxidation of $\mathrm{Sb}$ up to the temperature of $923 \mathrm{~K}$ to ensure the complete formation of the skutterudite phase.

Sintered compounds were produced by holding at $873 \mathrm{~K}$ or $923 \mathrm{~K}$ in vacuum. Another sintering was also carried out at $873 \mathrm{~K}$ in an $\mathrm{Ar}$ atmosphere, the condition used by Uchida et al. for comparison. Other parameters such as the heating rate, holding time and compression were kept constant for all specimens.

Figure 6 shows the temperature dependence of the Seebeck coefficient, $\alpha$ under different sintering conditions. The value of $\alpha$ is enhanced in the whole temperature range by changing the atmosphere from Ar to vacuum and by a rise of the sintering temperature from 873 to $923 \mathrm{~K}$. It is apparent that the formation of the skutterudite is enhanced as a result of the reduction of the oxidation of $\mathrm{Sb}$, and also the volume fraction of the residual $\mathrm{Sb}$ is reduced by holding at a higher temperature in vacuum. Figure 7 shows optical micrographs of sintered materials in vacuum at 873 and $923 \mathrm{~K}$. Residual Sb (white portion) is clearly seen along boundaries of atomized particles in the case of $873 \mathrm{~K}$. However, the amount of the residual Sb decreased drastically when the specimen was held at $923 \mathrm{~K}$ due to evacuation of melted $\mathrm{Sb}$ to the outside of the mold during sintering. We consider the phenomena described above to contribute to a decrease in the carrier concentration and, hence, an increase in $\alpha$.

Since the amount of $\mathrm{Sb}$, which serves as a good conductor both of electricity and heat, is reduced, both $\sigma$ and $\kappa$ decreased in the following order; $873 \mathrm{~K}$ in $\mathrm{Ar}, 873 \mathrm{~K}$ in vacuum and $923 \mathrm{~K}$ in vacuum as shown in Figs. 8 and 9.

A dimensionless figure of merit (ZT) calculated from $\alpha, \sigma$

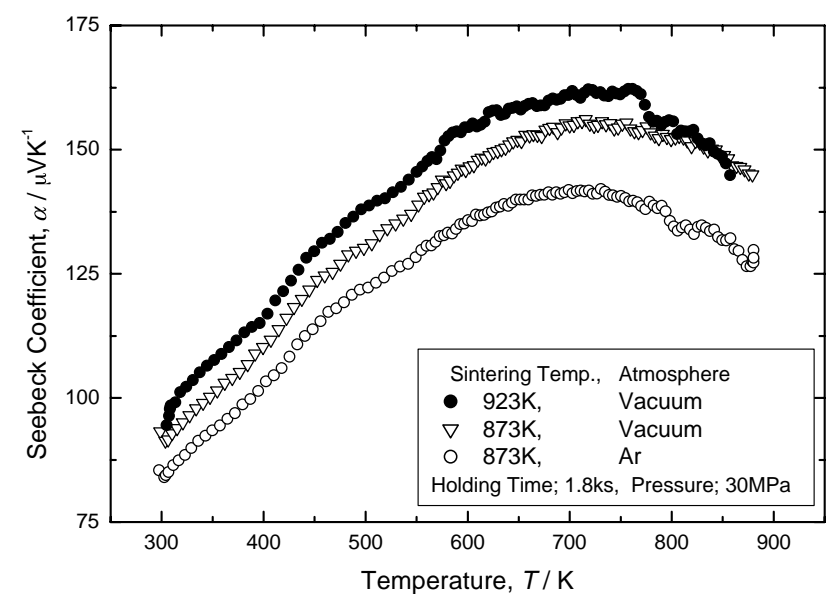

Fig. 6 Seebeck coefficient $(\alpha)$ as a function of temperature for $\mathrm{CeFe}_{3} \mathrm{CoSb}_{12}$ specimens under different sintering conditions.

and $\kappa$ is shown as a function of temperature in Fig. 10. In all specimens, $Z T$ values increase monotonously as the temperature increases until the maximum value is achieved at around $700 \mathrm{~K}$, and then start to decrease as the temperature further increases. The elaboration of sintering conditions resulted in a significant enhancement in $Z T$. The maximum $Z T$ value of 0.63 for the specimen sintered at $923 \mathrm{~K}$ in vacuum is obtained at $700 \mathrm{~K}$, which is 0.2 greater than that obtained at the same temperature for the specimen sintered at $873 \mathrm{~K}$ in an Ar atmosphere.

The maximum $Z T$ value obtained in this study is lower than the value of 0.9 at $700 \mathrm{~K}$ reported by Fleurial et al. ${ }^{2)}$ More specifically, at $700 \mathrm{~K}$, the value of $\alpha$ in this study is slightly lower than that of their report. $\sigma$ and $\kappa$ in this study are larger than each value of their report. The difference of these three thermoelectric properties between the two studies could be explained mainly by the still existing residual $\mathrm{Sb}$, as pointed out by Uchida et al. ${ }^{8)}$ Therefore, if the more residual $\mathrm{Sb}$ were pushed out from a compound during sintering, the smaller the difference would become. The optimum combination of the holding time and the pressure at high temperatures during sintering must be found out. 


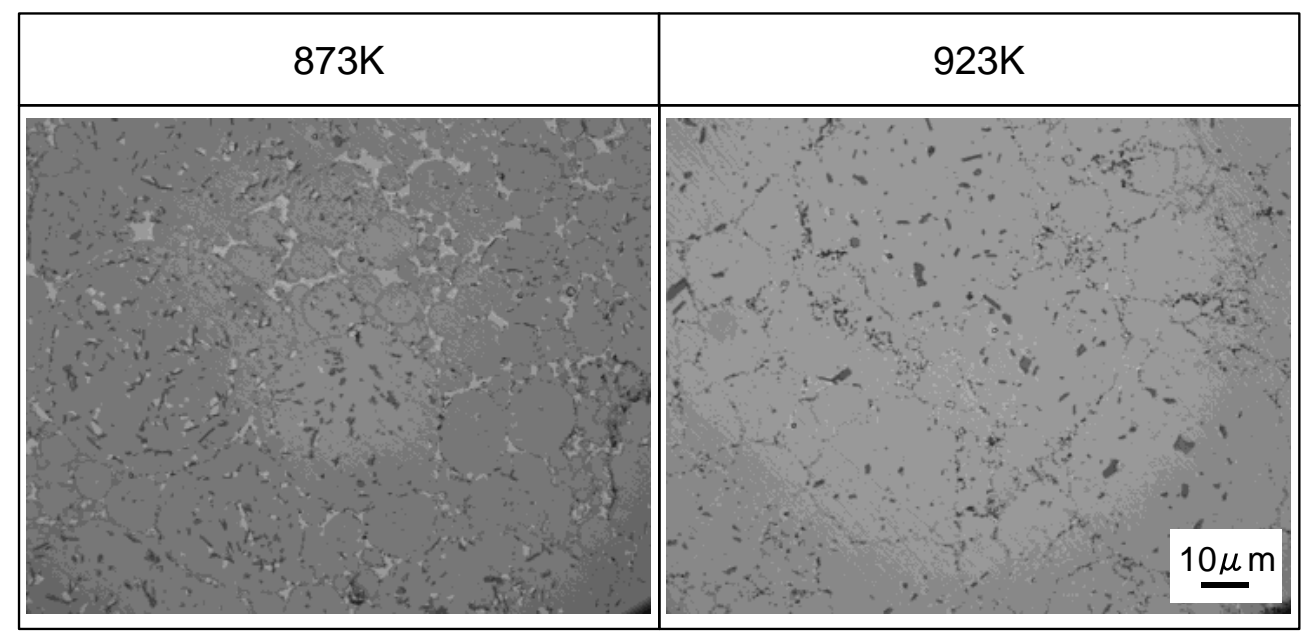

Fig. 7 Optical micrographs of $\mathrm{CeFe}_{3} \mathrm{CoSb}_{12}$ sintered at $873 \mathrm{~K}$ and $923 \mathrm{~K}$ for $1.8 \mathrm{ks}$ under $30 \mathrm{MPa}$.

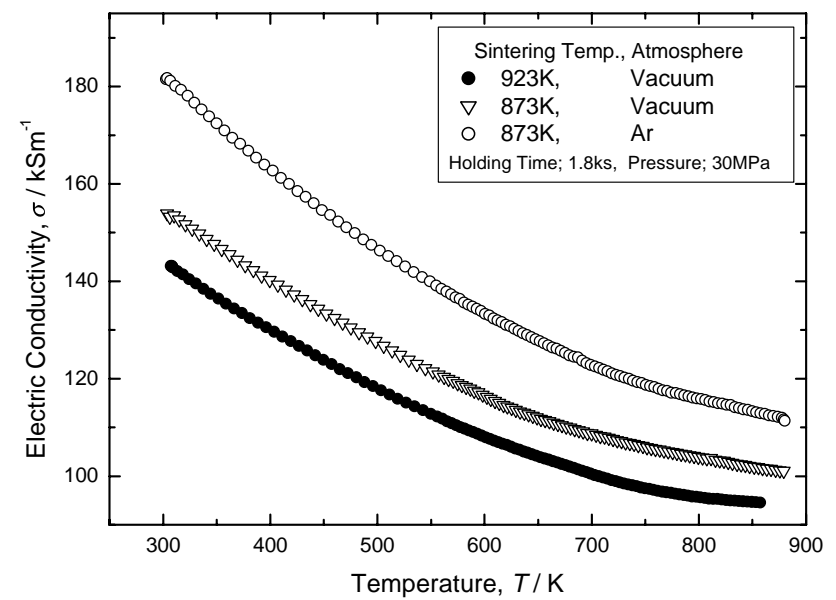

Fig. 8 Electrical conductivity $(\sigma)$ as a function of temperature for three sintered specimens.

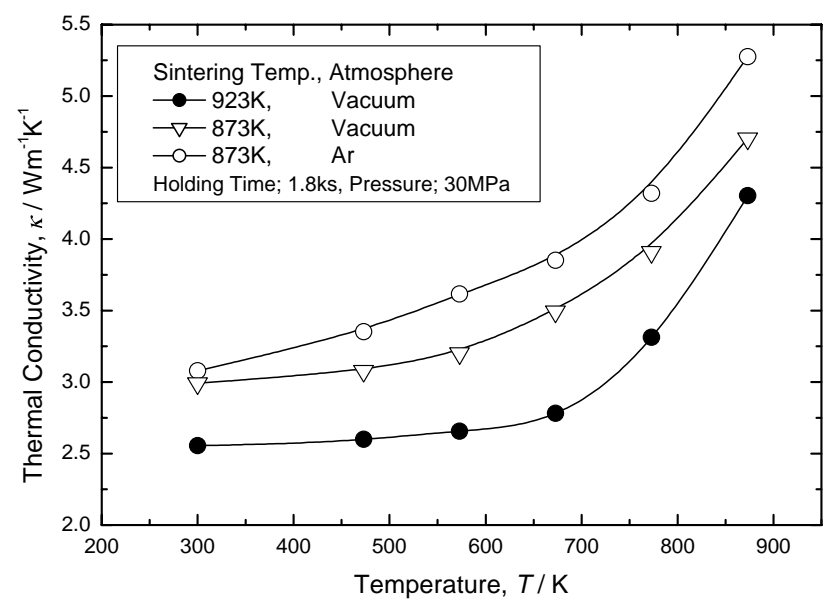

Fig. 9 Thermal conductivity $(\kappa)$ as a function of temperature for $\mathrm{CeFe}_{3} \mathrm{CoSb}_{12}$ specimens under different sintering conditions.

Reduction in the thermal conductivity by the filling of $\mathrm{Ce}$ ("rattling") may not function effectively in our specimens. As mentioned above, Ce-oxides already exist in atomized powder particles, and remain even after sintering. Since Ce is added under the assumption that the amount of Ce would be enough to fill the cavities in this study, the generation of $\mathrm{Ce}$ -

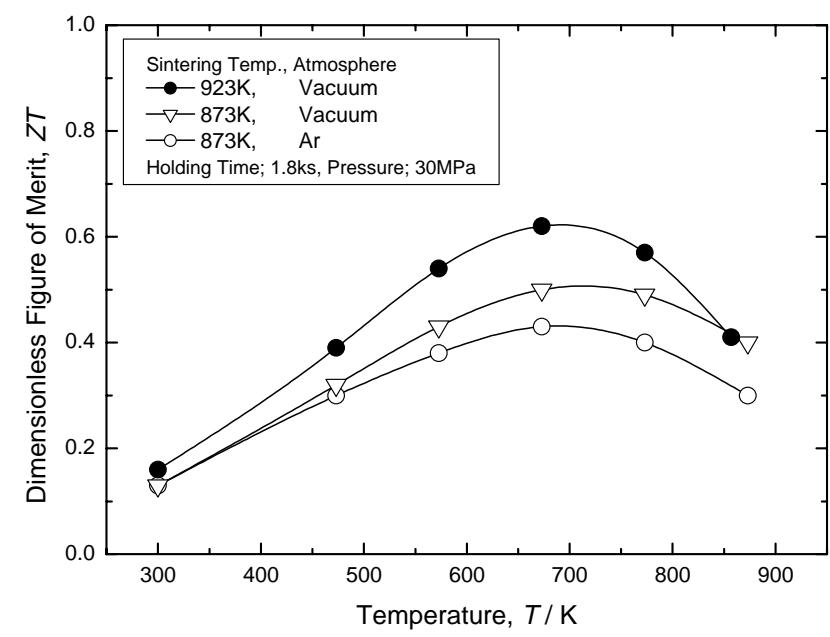

Fig. 10 Dimensionless figure of merit $(Z T)$ as a function of temperature calculated from $\alpha, \sigma$ and $\kappa$.

oxide causes the shortage of Ce-filling into cavities. And it is thought that this is another reason why the thermal conductivity has not been sufficiently improved.

Kitagawa et al. ${ }^{9)}$ presented the relationship between the XRD intensity ratio of (211) to (310) and the Ce-filling fraction $(f)$ in the melt-spun $\mathrm{Ce}_{f} \mathrm{Fe}_{8-x} \mathrm{Co}_{x} \mathrm{Sb}_{24}$ ribbon. Meisner et al. ${ }^{10)}$ reported the relationship between the Ce-filling fraction $(y)$ and lattice constants of $\mathrm{Ce}_{y} \mathrm{Fe}_{4-x} \mathrm{Co}_{x} \mathrm{Sb}_{12}$ with varying $y$. The value of $f$ or $y$ for the specimen showing the best $Z T$ value in this study (sintered at $923 \mathrm{~K}$ in vacuum) was estimated using both results. The value of $f=1.56$ was derived from the intensity ratio of $I_{211} / I_{310}=0.011$ in the former case, and the value of 1.56 is equivalent to $y=0.78$ in the latter notation, namely, $\mathrm{Ce}_{y} \mathrm{Fe}_{4-x} \mathrm{Co}_{x} \mathrm{Sb}_{12}$. While the lattice constant turned out to be as $0.9076 \mathrm{~nm}$, and it yielded the value of $y=0.46$ in the latter case.

The Ce-filling fraction is affected by the value of $x$, the substitution number of Fe by $\mathrm{Co}$, and $x$ is different between for our specimen and for theirs. Therefore it is not clear whether the Ce-filling fractions estimated above for our specimen are reasonable or not. Anyway, reducing the oxidation of $\mathrm{Ce}$ in atomizing process is required in order to enhance the 
Ce-filling fraction to 1.0.

It is reported that the fine oxide particles or layers reduce the thermal conductivity and improve the thermoelectric properties. ${ }^{11,12)}$ Although the permissible size of them for the effect has not been clarified, since the size of the Ce-oxides observed in this study is rather large up to several micrometers in the long axis (see Fig. 7), they might exert negative effects on the thermoelectric properties.

Ce-oxides are thermodynamically very stable. For example, the standard free energy of formation $\left(\Delta G^{0}\right)$ for $\mathrm{Ce}_{2} \mathrm{O}_{3}$ and $\mathrm{CeO}_{2}$ at $500 \mathrm{~K}$ is $-1676.9 \mathrm{KJ} / \mathrm{mol}$ and $-983 \mathrm{KJ} / \mathrm{mol}$, respectively. ${ }^{13)}$ Since the standard free energy of formation for $\mathrm{H}_{2} \mathrm{O}$ is $-219.0 \mathrm{KJ} / \mathrm{mol},{ }^{13)} \mathrm{Ce}$-oxides could not be reduced by heat-treatment even in a hydrogen atmosphere. From the above, controlling the oxidation of $\mathrm{Ce}$ as low as possible during atomization is strongly desired to achieve excellent thermoelectric properties. And keeping as small size of Ce-oxides as possible might be also effective. The former will become possible by using some kind of Ce alloy (e.g. Ce-Fe) instead of pure $\mathrm{Ce}$, the latter by accelerating cooling speed in the injection (solidification) process of gas-atomization.

\section{Conclusion}

The formation of Ce-filled skutterudite thermoelectric materials sintered from gas-atomized powder was investigated. The conclusions obtained in this work are as follows;

(1) A gas-atomized powder particle of $\mathrm{CeFe}_{3} \mathrm{CoSb}_{12}$ consists of a skutterudite phase, $\mathrm{FeSb}_{2}, \mathrm{FeSb}$ and $\mathrm{Sb}$.

(2) The oxidation of $\mathrm{Sb}$ and the formation of the skutterudite phase take place during sintering in the written order.

(3) Adjusting of the sintering conditions to minimize the oxidation of $\mathrm{Sb}$ and to ensure the formation of skutterudite causes increases in the Seebeck coefficients and decreases in the electrical conductivities and the thermal conductivity simultaneously. Such results are attained mainly by decreasing the residual $\mathrm{Sb}$ in sintered materials.

(4) The highest value 0.63 of $Z T$ is obtained at $700 \mathrm{~K}$ for the material sintered at $923 \mathrm{~K}$ in vacuum.

(5) Controlling the oxidation of $\mathrm{Ce}$ as low as possible is necessary in order to enhance Ce-filling fraction.

\section{Acknowledgements}

This work was supported by the Yamaguchi Prefectural Government and the New Energy and Industrial Technology Development Organization of Japan. The authors would like to thank Ms. A. Nishihama and Ms. E. Tanaka of the Japan Ultra-high Temperature Materials Research Institute for their help in conducting the experiments described in this paper.

\section{REFERENCES}

1) J.-P. Fleurial, T. Caillat and A. Borshchevsky: Proc. 16th Int. Conf. on Thermoelectrics, (IEEE, 1997) pp. 1-11.

2) J.-P. Fleurial, A. Borshchevsky and T. Caillat: Proc. 15th Int. Conf. on Thermoelectrics, (IEEE, 1996) pp. 91-95.

3) D. M. Rowe, V. L. Kuznetsov and L. A. Kuznetsova: Proc. 17th Int. Conf. on Thermoelectorics, (IEEE, 1998) pp. 323-325.

4) H. Nakagawa, H. Tanaka, A. Kasama, K. Miyamura, H. Masumoto and K. Matsubara: Proc. 15th Int. Conf. on Thermoelectorics, (IEEE, 1996) pp. 117-121.

5) H. Uchida, V. Crnko, H. Tanaka, A. Kasama and K. Matsubara: Proc. 17th Int. Conf. on Thermoelectorics, (IEEE, 1998) pp. 330-333.

6) H. Tanahashi, Y. Ohta, H. Uchida, A. Kasama, Y. Itsumi and K. Matsubara: Proc. 19th Int. Conf. on Thermoelectorics, (IEEE, 2000) pp. 94-97.

7) C. Uher, S. Hu and J. Yang: Proc. 17th Int. Conf. on Thermoelectorics, (IEEE, 1998) pp. 306-309.

8) H. Uchida, A. Kasama, Y. Itsumi and K. Matsubara: Proc. 18th Int. Conf. on Thermoelectorics, (IEEE, 1999) pp. 454-457.

9) H. Kitagawa, M. Hasaka, T. Morimura, H. Nakashima and S. Kondo: Mater. Res. Bull. 35 (2000) 185-192.

10) G. P. Meisner, D. T. Morelli, S. Hu, J. Yang and C. Uher: Phys. Rev. Lett. 80 (1998) 3551-3554.

11) Y. H. Lee, R. Isobe, M. Yomura, I. Nakano and T. Koyanagi: Proc. 16th Int. Conf. on Thermoelectorics, (IEEE, 1997) pp. 203-206.

12) T. Koyanagi, K. Kishimoto, Y. H. Lee and Y. Nagamoto: J. Japan Inst. Metals 62 (1998) 1075-1081 (in Japanese).

13) E. A. Brandes and G. B. Brook: Smithells Metals Reference Book 7th Ed., (Butterworth-Heinemann, Oxford, 1992) Chap. 8-25, 26. 